EEESTI NSV TEADUSTE AKADEEMIA TOIMETIISED. 31. KOIDE GEOLOOGIA. 1982, NR. 1

ИЗВЕСТИЯ АҚАДЕМИИ НАУК ЭСТОНСКОП ССР. ТОМ 31

ГЕОЛОГИЯ. 1982, № 1

Э. ПНРРУС

удК $549.762 .13: 551.732(474.2)$

\title{
ЯРОЗИТ - ПРОДУКТ СОВРЕМЕННОГО ГИПЕРГЕНЕЗА В ПОРИСТЫХ АЛЕВРОЛИТАХ КЕМБРИЯ ЭСТОНИИ
}

При изучении глинистых минералов кембрийских отложений Северной Эстонии в хорошо отсортированных алевролитах и песчаниках тискре ской свиты внимание исследователей привлекала интенсивно-желтая пигментация порового пространства выветрелых разновидностей этих пород. Нередко фракция $<0,001$ мм, вымытая из этих пород, давала дополнительные рефлексы гетита, иногда очень слабый рефлекс в $6,25 \AA$ давали следовые количества дисперсного лепидокрокита. Однако прямой корреляции между интенсивностью охристо-желтой пигментации и содержанием гидроокислов железа в этих пробах не отмечено. Это вызвало интерес к более подробному исследованию данного явления.

В 1980 г. в обнажении Утрия на северо-востоке Эстонии был исследован участок выхода крупнозернистых алевролитов тискреской свиты, в порах которых обнаружено богатое скопление ярко-желтой землистой массы без признаков присутствия заметного количества глинистого вещества. Эта масса маркировала в породе тонкие (около 1 мм) слойки, которые, в свою очередь, концентрировались в серии, местами создавая впечатление сплошной импрегнации алевритового скелета этим минералом. Отдельные слойки с таким заполнением пор увеличиваются по мощности до 2-3 мм, приобретая более интенсивный буроватый оттенок и бо́льшую цементацию. В основном описанная желтая масса наблюдается в приповерхностной 3-4-метровой зоне выветриваиия алевролитов, постепенно ослабевая вглубь обнажения.

При обработке таких алевролитов дистиллированной водой получается сравнительно устойчивая суспензия, позволяющая провести раз-

Содержание отдельных компонентов по фракциям изученных пород, \%

\begin{tabular}{|c|c|c|c|c|c|c|}
\hline \multirow[b]{2}{*}{ Проба } & \multirow[b]{2}{*}{ Компоненты } & \multirow[b]{2}{*}{ 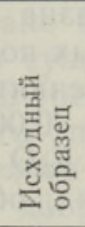 } & \multicolumn{4}{|c|}{ Содержание по фракциям } \\
\hline & & & $\begin{array}{l}\overline{0} \\
\dot{1}\end{array}$ & $\frac{12}{0}$ & $\begin{array}{l}5 \\
8 \\
0 \\
1 \\
10 \\
8 \\
0 \\
0\end{array}$ & $\begin{array}{l}\vdots \\
\vdots \\
\overline{8} \\
0 \\
\dot{0}\end{array}$ \\
\hline $\begin{array}{l}\text { Алевролит } \\
\text { с ярко-жел- } \\
\text { той цемен- } \\
\text { тирующей } \\
\text { массой }\end{array}$ & $\begin{array}{c}\mathrm{Fe}_{2} \mathrm{O}_{3} \\
\mathrm{~K}_{2} \mathrm{O} \\
\mathrm{Pacq} \\
\mathrm{KFe}_{3}\left(\mathrm{SO}_{4}\right)_{2}(\mathrm{OH})_{6}\end{array}$ & $\begin{array}{l}1,19 \\
2\end{array}$ & $\begin{array}{l}0,49 \\
1\end{array}$ & 4,65 & $\begin{array}{r}18,53 \\
5,72 \\
38\end{array}$ & \\
\hline $\begin{array}{l}\text { Алевролит с } \\
\text { коричневато- } \\
\text { желтой це- } \\
\text { ментирую- } \\
\text { щей массой }\end{array}$ & $\begin{array}{c}\mathrm{Fe}_{2} \mathrm{O}_{3} \\
\mathrm{~K}_{2} \mathrm{O} \\
\mathrm{Pacqeтное} \text { содержание ярозита } \\
\mathrm{KFe}_{3}\left(\mathrm{SO}_{4}\right)_{2}(\mathrm{OH})_{6}\end{array}$ & 1,42 & 0,83 & $\begin{array}{r}32,90 \\
6,16 \\
69\end{array}$ & $\begin{array}{r}39,92 \\
6,45 \\
83\end{array}$ & $\begin{array}{r}26,40 \\
5,14 \\
55\end{array}$ \\
\hline
\end{tabular}




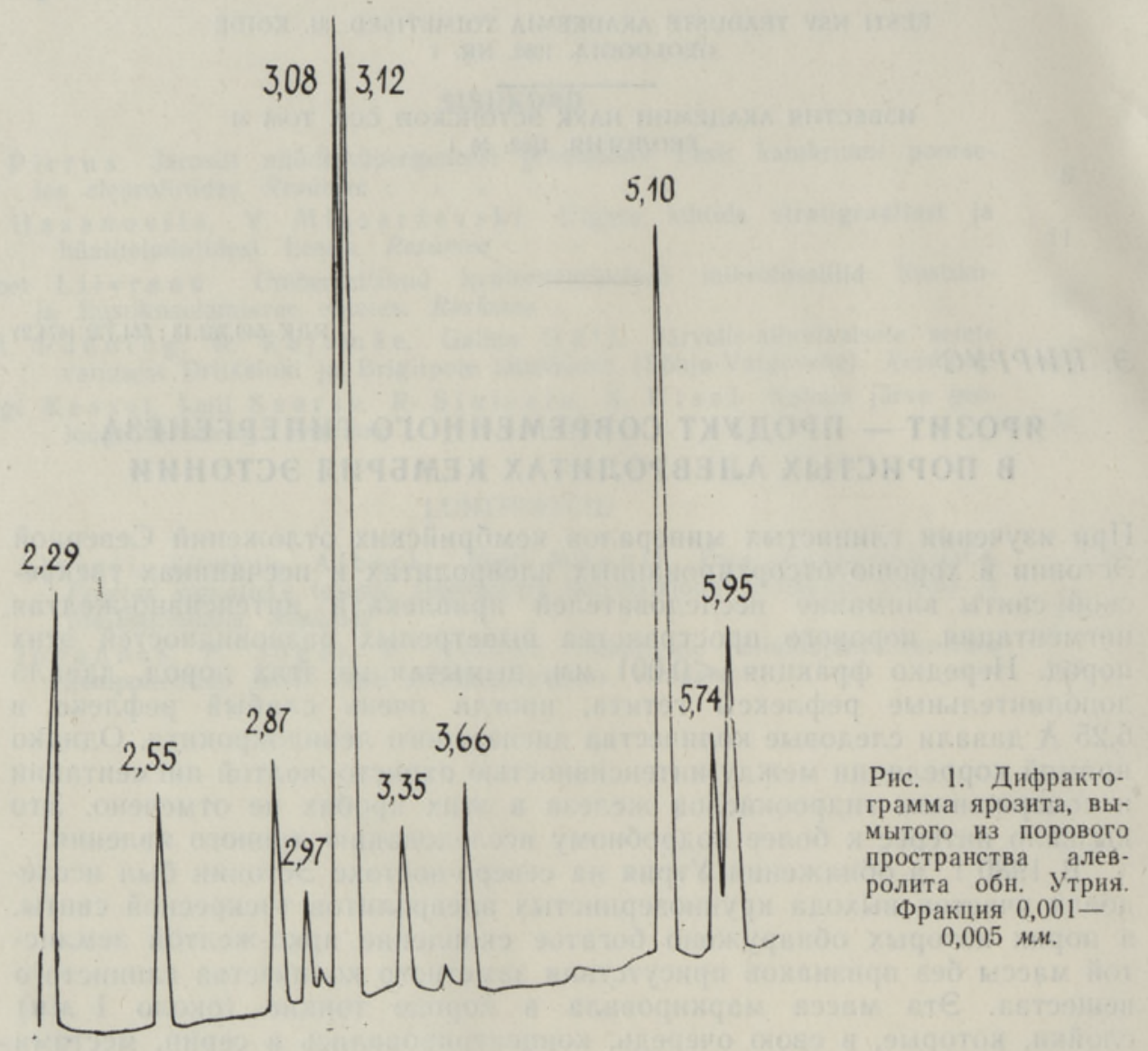

деление породы на фракции $>0,01,0,01-0,005,0,005-0,001$ и $<0,001$ мм. Фракция >0,01 мм во всех случаях представлена почти чистым кварцем, отражающим основной алевритовый скелет породы. Содержание железа в ней минимально (таблица).

Дисперсные фракции изучались рентгенометрически на дифрактометре ДРОН-2,0 и химически. Оказалось, что желтый минерал, сконцентрированный в этих фракциях, является ярозитом - двойным сульфатом калия и железа в его почти идеальном структурном выражении (рис. 1). Так, дифракционная картина полностью сходится с рентгенограммой эталонного образца американской картотеки (Selected..., $1974)$, а соотношения главных породообразующих компонентов - $\mathrm{Fe}_{2} \mathrm{O}_{3}$ и $\mathrm{K}_{2} \mathrm{O}$ - близки к соотношениям их по формуле минерала (таблица). Гіри этом во фракции 0,005-0,001 мм у первой и $<0,001$ мм у второй пробы отмечается избыток $\mathrm{K}_{2} \mathrm{O}$ по сравнению с содержанием его по формуле, что, на наш взгляд, объясняется присутствием в этих фракциях дополнительного носителя калия - гидрослюдистых глинистых минералов. Во фракциях $0,01-0,005$ и $0,005-0,001$ мм у второй пробы, наоборот, наблюдается дефицит $\mathrm{K}_{2} \mathrm{O}$ по сравнению с содержанием железа, что может быть обусловлено наличием небольшого количества $\mathrm{Fe}_{2} \mathrm{O}_{3}$ в форме рентгеноаморфных окислов. Замещение части $\mathrm{K}_{2} \mathrm{O}$ на $\mathrm{Na}_{2} \mathrm{O}$ в данном случае не имеет места, так как содержание натрия во всех изученных фракциях мизерное.

Известно, что ярозит характерен для зоны окисления сульфидных месторождений засушливых областей, где он формируется при сернокислом выветривании пирита, пирротина и других железосодержащих 


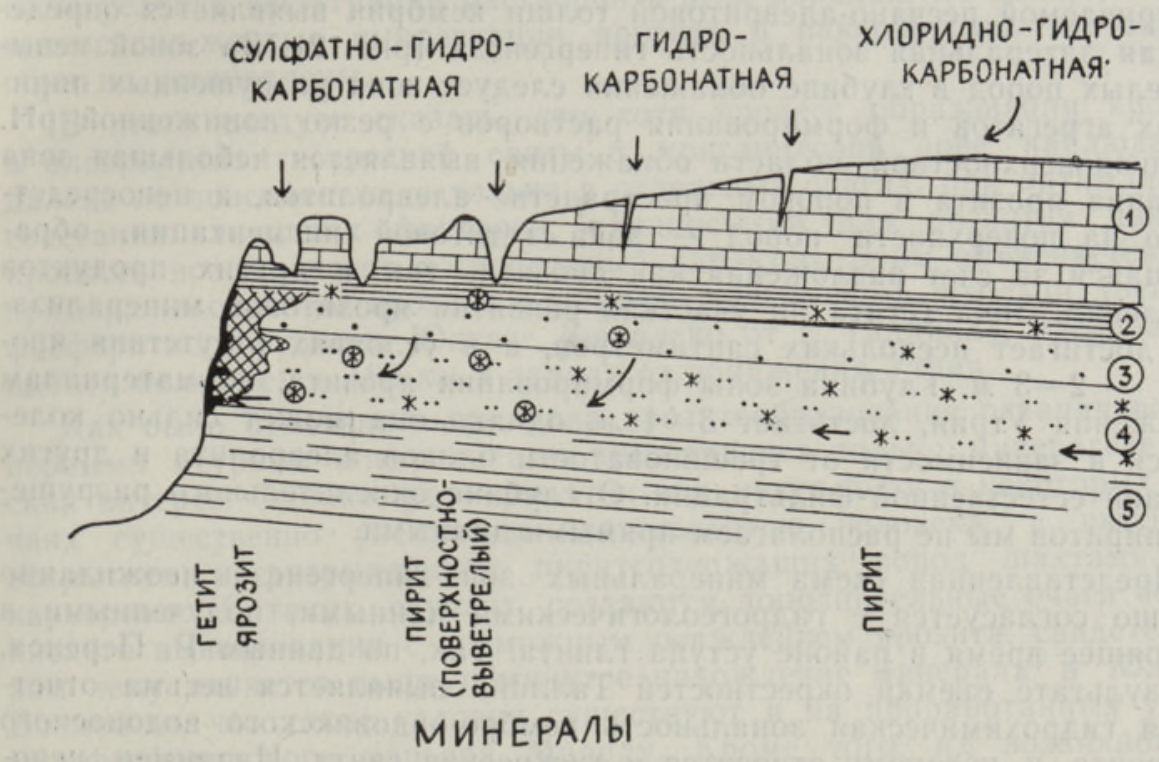

Рис. 2. Принципиальная схема зональности минералообразования и химизма грунтовых вод в районе Северо-Эстонского глинта. 1 - известняк, 2 граптолитовый (диктионемовый) сланец, 3 - песчаники пакерортского горизонта ордовика, 4 - алевролиты тискреской свиты кембрия, 5 - глины и алевролиты люкатиской свиты кембрия.

сульфидов (Чухров, 1950; Байбулатов, 1961 и др.). В условиях более низкой кислотности среды окисления $(\mathrm{pH}>3,5)$ сульфаты железа не образуются или быстро разлагаются в процессе гидролиза, давая обычные гидроокисные формы железа. Поэтому в умеренно-влажных климатических обстановках этот минерал является экстремным и указывает на локальные специфические условия формирования.

Каковы эти условия в районе Северо-Эстонского глинта? Во-первых, ӭто обилие тонкокристаллических агрегатов пирита в хорошо проницаемых алевролитах и песчаниках тискреской свиты, которые обеспечивали процесс минералообразования как в части доставки необходимых количеств железа и серы, так и в части создания требуемой кислотности поровых растворов. Во-вторых, этә отсутствие или малая мощность покрова карбонатных пород вышележащих горизонтов палеозоя у кромки глинта, что обеспечивало фильтрацию атмосферных вол до уровня минералообразования без существенного захвата нейтрализующих растворенных карбонатов. В-третьих, это наличие слоев диктионемового аргиллита пакерортского горизонта и рыхлого глауконитового песчаника латорпского горизонта выше тискреской свиты, что обеспечивало, по всей вероятности, достаточное содержание калия в растворах минералюобразования. Поступление ионов калия в эту среду могло происходить частично и за счет выветривания обильного глауконита в тискреском алевролите, однако макроскопически зерна этого минерала сохраняют свежую ярко-зеленую окраску и у самой поверхности выхода, включая также зону с ярозитом. И наконец, сезоннопериодическая насыщенность алевролитов тискреской свиты грунтовой водой и существенное значение ветрового испарения ее при выходе на приподнятом участке глинта создали условия для осаждения части сульфатов непосредственно в порах пород и препятствовали их полному выносу из описываемого пространства минералообразования. 
В результате сочетания этих факторов на выходных блоках рассматриваемой песчано-алевритовой толщи кембрия выявляется определенная латеральная зональность гипергенеза (рис. 2). За зоной невыветрелых пород в глубине обнажения следует зона разрушенных пиритовых агрегатов и формирования растворов с резко пониженной $\mathrm{pH}$. В близповерхностной области обнажения выявляется небольшая зоңа оседания ярозита в поровом пространстве алевролитов, а непосредственно на поверхности пород - зона гетитовой пигментации, образующаяся за счет разложения как ярозита, так и других продуктов окисления. Зона гетита на участках развития ярозитовой минерализации достигает нескольких сантиметров, а в условиях отсутствия ярозита $-2-3$ м. Глубина зоны формирования ярозита, по материалам обнажения Утрия, достигает $3-4$, однако она может сильно колебаться в зависимости от трещиноватости блоков алевролита и других условий естественной фильтрации. О глубине окислительного разрушения пиритов мы не располагаем прямыми данными.

Представленная схема минеральных зон гипергенеза неожиданно хорошо согласуется с гидрогеологическими данными, полученными в настоящее время в районе уступа глинта. Так, по данным Р. Перенса, в результате съемки окрестностей Таллина выявляется весьма отчетливая гидрохимическая зональность кембро-ордовикского водоносного горизонта, к которому относится и тискреская свита. Например, непосредственно у кромки глинта в пределах небольшой зоны во́ды имеют сульфатно-гидрокарбонатный состав, а несколько южнее - в зоне выдержанного карбонатного надстила - гидрокарбонатный состав. Дальше на юг республики, где данный водоносный горизонт погружается на бо́льшие глубины и где динамика вод уже не подвергается прямому. воздействию атмосферных и поверхностных вод, грунтовые воды приобретают хлоридно-гидрокарбонатный состав. Компонентный состав воды в сульфатно-гидрокарбонатной зоне, по данным А. Пилль, следующий: в Раннамыйза общая минерализация 308 мә/, $\mathrm{HCO}_{3}$ 238 мг/л $(71 \%), \mathrm{SO}_{4} 58,8$ мг/л $(22 \%), \mathrm{Cl} 14,3 \mu 2 / \Omega(7 \%)$; в Харку общ. мин. $409 \mu г / \Omega, \mathrm{HCO}_{3} 219,7 \mu 2 / \Omega(52 \%), \mathrm{SO}_{4} 140 \mu г / \Omega(43 \%), \mathrm{Cl} 10,8 \mu г / \Omega$ $(5 \%)$; в Кейла-Иоа общ. мин. 308 ма/ $\Omega, \mathrm{HCO}_{3} 207,5$ ма/л $(60 \%), \mathrm{SO}_{4}$ 85 ма/л $(31 \%), \mathrm{Cl} 18,9$ мг/л $(9 \%)$. Кислотность и содержание Fe в этих водах не изучено. Естественно, эти данные ни в коем случае не характеризуют химизм растворов зоны ярозитообразования, однако они однозначно свидетельствуют о том, что сульфатный ион играет весьма существенную роль в водах зоны уступа глинта, и не исключено его становление в локальных экстремных условиях резко преобладающим анионом. Эти данные свидетельствуют также о поступлении сульфатного иона именно в ходе разложения осадочного тонковкрапленного или конкреционного пирита; влияние инфильтрации морских вод в этих прибрежных породах-коллекторах нереально из-за низкого содержания в водах хлор-иона. Кстати, такое влияние на уступе глинта исключается и геоморфологически - высоким гипсометрическим положением кембро-ордовикского водоносного горизонта относительно уровня моря.

Интерес представляет узкий стратиграфический диапазон ярозитопроявления: вниз по разрезу его развитие тормозит толща непроницаемых «синих глин» кембрия (люкатиская и лонтоваская свиты), вверх близость карбонатной вскрыши - поставщика нейтрализующего карбонатного составляющего. Не совсем ясна возможность формирования ярозита в песчаниках вышележащего пакерортского горизонта, который образует вместе с породами тискреской свиты единый кемброордовикский водоносный горизонт. Возможно, что здесь играет отрицательную роль более грубый состав песчаников ордовика, определяющий 
иные условия фильтрации растворов в этих породах. Во всяком случае интенсивно-желтые импрегнации ярозита в пакерортских песчаниках пока не установлены.

В итоге следует сказать, что хотя процесс образования ярозита в алевролитах тискреской свиты в приглинтовой зоне наблюдается далеко не повсеместно, а только в отдельных очагах, при оптимальном сочетании влияющих факторов, предпосылки для развития данного процесса все же носят региональный характер. Этим объясняется, например, нахождение ярозита в цементе алевролитов штольни древнего фосфоритного рудника Юлгазе (недалеко от г. Таллина), располагающегося более чем в $180 \kappa м$ к западу от обчажения Утрия.

Как было отмечено выше, зона ярозитообразования ограничивается первыми метрами алевролита и представляет только минерагенетический интерес. Однако, размеры этих зон могут быть в некоторых случаях существенно увеличены деятельностью человека, в частности вскрытием и разрыхлением пиритсодержащих пород шахтами или карьерами. В таких случаях создаются дополнительные очаги сернокислого выветривания с возможным осаждением ярозита, свидетельством чему является вышеупомянутое нахождение минерала в Юлгазе. Возможно, что такие условия существуют и на проработанных участках фосфоритового карьера Маарду. Кроме того, их возникновение вполне вероятно и в будущем на планируемом крупном руднике фосфоритов в Тоолсе. К сожалению, геологическая документация этих минералопроявлений до сих пор не проводилась, как и целенаправленное изучение химизма вод в действующих фосфоритовых карьерах и в естественных обнажениях с минерализацией ярозита.

Находка ярозита на Северо-Эстонском глинте, а также в аналогичной форме в других регионах мира (Briggs, 1951; Mitchell, 1962; Warshaw, 1956 и др.) свидетельствует о том, что этот минерал не столь уж редок в гумидных условиях умеренных широт, как это отмечается обычно в руководствах по минералогии (Бетехтин, 1956; Годовиков, 1975). Недоценка его роли в современном гипергенезе объясняется, по-видимому, недостаточно точной диагностикой минерала. Как показывает рассмотренный пример, в благоприятных геологических условиях ярозит формируется как нормальный промежуточный продукг окисления осадочных пиритов, содержащихся иногда в больших количествах в осадочных породах нормально-морского происхождения. Зона формирования ярозита представляет собой специфический геохимический барьер для целой группы анионов и катионов, имеющий иногда важное практическое значение, особенно при разрыхлении больших масс пиритсодержащих пород в горных выработках. Поэтиму данному явлению в современном гипергенезе следует уделять должное внимание.

\section{Л И ТЕРАТУРА}

Бай 6 ул а то в Э. Б. О некоторых сульфатах железа из зоны окисления АчикТашского серноколчеданного месторождения. - Зап. Киргизского отд. Всес. мин. общ., 1961, вып. 2, 65-75.

Бетехтин А. Г. Курс минералогии. М., 1956.

Год о в и ко в А. А. Минералогия. М., 1975.

Чухров Ф. В. Зона окисления сульфидных месторождений степной части Казахстана. М., 1950.

Brigg s, L. J. Jarosite from the California Tertiary. - Amer. Mineralogist, 1951, 36, 902-906.

Mitchell, R. S. New occurence of jarosite in Virginia, - Amer, Mineralogist, 1962, $47,788-789$, 
Selected Powder diffraction data for mineral search manual. DBM-1-23. Philadelphia, 1974.

Warsh a w, C. M. The occurence of jarosite in underclays. - Amer. Mineralogist, 1956, 41, $288-296$.

Ннститут геологии

Академии наук Эстонской ССР

Поступила в редакцию

$18 / \mathrm{V} 1981$

\section{E. PIRRUS}

\section{JAROSIIT NUUDISHUPERGENEESI PRODUKTINA EESTI KAMBRIUMI POORSETES ALEUROLIITIDES}

Artiklis on kirjeldatud peendispersse jarosiidi leide Pōhja-Eesti klindil avanevates tiskre kihistu aleuroliitides. Mineraal tekib hajusa püriidikülvi oksüdatsiooniproduktidest, mis sulfaatsete lahustena kanduvad vete väljumistsooni klindiseinal, kus jarosiit sadestub. See protsess on heas kooskõlas vastava pōhjaveetaseme vete anioonkoostises k'indi.ähedasel alal ilmneva vööndilisusega. On võimalik, et fosforiidi kaevandamisega kaasnev pinnase kobestumine ja filtratsioonitingimuste mutumine loovad 'isaeeldusi jarosiidi tekkeks.

\section{E. PIRRUS}

\section{JAROSITE AS A PRODUCT OF CONTEMPORARY HYPERGENESIS IN POROUS SILTSTONES OF THE ESTONIAN CAMBRIAN}

Finds of fine-dispersed jarosite in the siltstones of the Tiskre Formation, opening on the North-Estonian G'int, have been described. This mineral has been formed here from oxydation products of dispersed pyrite grains and transported as an ingredient of the sulphatic solution in the rocks up to the outflow zone of the water on the glint wall. This process is in good harmony with the hydrochemical zonality of the anion composition oi the corresponding underground water-level in the nearglint area.

The examined process is intensified by the mining works carried out on the phosphorite deposits. 